\title{
Analysis of feasibility, safety and effectiveness of ultrasound-guided percutaneous microwave ablation of splenic neoplasm
}

\author{
NA LUO ${ }^{1}$, YAN WANG ${ }^{1}$, ZHE GENG $^{1}$ and XIANTAO QIN ${ }^{2}$ \\ Departments of ${ }^{1}$ Ultrasonography and ${ }^{2}$ General Surgery, The Second People's Hospital \\ of Liaocheng, Linqing, Shandong 252600, P.R. China
}

Received October 13, 2017; Accepted December 18, 2017

DOI: 10.3892/ol.2018.7845

\begin{abstract}
The present study aimed to analyze the feasibility, safety and effectiveness of ultrasound-guided percutaneous microwave ablation of splenic neoplasm. A total of 62 patients with splenic neoplasm admitted to Second People's Hospital of Liaocheng between January 2009 and December 2012 were selected, and randomly divided into the observation group $(n=31)$ and control group $(n=31)$. The control group was treated with open ablation, while the observation group was treated with ultrasound-guided percutaneous microwave ablation. The splenic hemodynamics and ablation effects of patients after treatment were detected via color Doppler ultrasound. The changes in peripheral blood cell count before treatment, and at 3, 7 and 14 days after treatment were monitored. The side effects and complications were compared between the two groups. Patients were followed up for 5 years to observe the survival rates of the two groups. At 1 week after treatment, the peak velocity of splenic artery in observation group was significantly lower than that in control group, and the diameter, velocity and flow of splenic vein were significantly lower than those in control group $(\mathrm{P}<0.05)$. After treatment, the white blood cell and platelet counts in both groups were significantly increased compared with those before treatment, and the counts in observation group were obviously higher than those in control group $(\mathrm{P}<0.05)$. There were no significant changes in the red blood cell counts in both groups before and after treatment $(\mathrm{P}>0.05)$. The ablation volume, ablation ratio and 1-week shrink ratio in both groups had no significant differences $(\mathrm{P}>0.05)$. The incidence rates of side effects and complications in observation group were significantly lower than those in control group $(\mathrm{P}<0.05)$. The 5-year survival rates
\end{abstract}

Correspondence to: Dr Xiantao Qin, Department of General Surgery, The Second People's Hospital of Liaocheng, 306 Jiankang Street, Linqing, Shandong 252600, P.R. China

E-mail: hanxiaoxiao120@163.com

Key words: ultrasound-guided, microwave ablation, splenic neoplasm of both groups were $>50 \%$, and the survival time and survival rate were not significantly different $(\mathrm{P}<0.05)$. The curative effects of open ablation and ultrasound-guided percutaneous microwave ablation in the treatment of splenic neoplasm were significant, and the 5-year survival rate of patients was higher; compared with open ablation. The ultrasound-guided percutaneous microwave ablation is characterized by the small trauma, lower incidence rates of adverse reactions and complications and better safety, which can increase the peripheral blood cell count, and improve the splenic blood flow and coagulation function, playing a role in the regulation of the patient's body status.

\section{Introduction}

Splenic neoplasm is a kind of clinically rare disease, and its incidence rate is lower compared with other common tumors (1). However, with the changes in living habits and dietary structure and the accelerated environmental pollution, there are increasingly more pathogenic factors of splenic neoplasm, and its incidence rate shows an increasing trend. Splenic neoplasm is difficult to be detected early and its misdiagnosis rate is high due to that its clinical manifestations are not specific (2). However, with the continuous improvement of imaging technique, the detection rate of spleen neoplasm is gradually increased. Consequently, the proportion in the diagnosis and treatment of the tumors also shows a rising trend, posing a serious threat to the human life and health (3). The treatment methods of splenic neoplasm mainly include the splenic artery embolization, splenectomy, splenic hilar lymph node dissection (4). The best opportunity of surgical resection for patients has often been lost because splenic neoplasm is often in the middle and advanced stage once diagnosed. Combined with the importance of spleen in immune function, the spleen preserving treatment methods are gradually recognized by medical staffs and patients in clinic (5).

The microwave ablation therapy belongs to the thermal coagulation therapy, characterized by small trauma, repeatability and definite efficacy, which has gradually become a preferred method for non-surgical patients, especially those organ tumor patients with abundant blood supply (6). 
The primary purpose of this study was to investigate the feasibility, safety and effectiveness of ultrasound-guided percutaneous microwave ablation of splenic neoplasm.

\section{Patients and methods}

Patient selection. A total of 62 patients with splenic neoplasm admitted to our hospital from January 2009 to December 2012 were selected and randomly divided into control group $(\mathrm{n}=31)$ and observation group $(\mathrm{n}=31)$ using the random number table. Inclusion criteria: i) patients diagnosed as splenic neoplasm via imaging and pathological examination; ii) patients with malignant tumor; and iii) patients who signed the informed consent. Exclusion criteria: i) patients with abnormal coagulation function; and ii) patients with a previous history of surgery, chemotherapy or radiotherapy. This study was approved by the Ethics Committee of the Second People's Hospital of Liaocheng. Signed written informed consents were obtained from all participants before the study. There were no statistically significant differences in the general data between the two groups $(\mathrm{P}>0.05$; Table I).

Instruments and equipment. KY-2000 water-cooled microwave therapy apparatus (Nanjing Canyou Medical Technology Co., Ltd. Nanjing, China), working frequency: 2,450 MHz, output power: 1-100W; low-loss coaxial cable transmission is connected to electrode, electrode diameter: $1.9 \mathrm{~mm}$, length: $180 \mathrm{~mm}$, and the microwave gap emission is $10 \mathrm{~mm}$ away from the tip, emission gap: $3.0 \mathrm{~mm}$. Lange BTDI-100 peristaltic pump (Baoding Lange Constant Flow Pump Co., Ltd., Baoding, China) as the water cycle power pump, flow rate: $30 \mathrm{ml} / \mathrm{min} ; 20^{\circ} \mathrm{C}$ sterile saline solution as the cooling water.

Ultrasonic instrument: PhilipsiU22 color Doppler ultrasound diagnostic apparatus (Philips, Amsterdam, Netherlands) was used for abdominal ultrasound contrast, frequency of variable frequency probe: $2.5-5.0 \mathrm{MHz}$, harmonic frequency: $2.5-3.5 \mathrm{MHz}$, speed range: $0.06-0.12 \mathrm{~m} / \mathrm{s}$. SonoVue (manufacturer: Milan Bracco, registration no. H20080059, specifications: $59 \mathrm{mg}$ sulfur hexafluoride gas and freeze-dried powder $25 \mathrm{mg} /$ bottle, Milan, Italia) was used as the contrast agent.

Treatment protocols for two groups. Before operation, patients in both groups underwent the ultrasound contrast and enhanced CT examination to understand the lesion, and color Doppler ultrasound to detect the blood flow distribution in splenic artery, creating the conditions for the selection of microwave spleen ablation approach and ablation area. The control group was treated with the open ablation: Under the trachea cannula, the left back of the patient was raised for $30^{\circ}$ in an oblique position, and the right side of the rib margin was cut, and the abdominal wall was cut layer by layer to expose the spleen. After that, the microwave ablation electrode was inserted at a depth according to the ablation area, without damaging the surrounding organs and hilum of spleen. Under the power of $80 \mathrm{~W}, 1-7$ needles were used for ablation and lasted for 5-50 min for each needle, and the abdomen was sutured after there was no active bleeding in the spleen.

The observation group was treated with the ultrasoundguided percutaneous microwave ablation: The ultrasound instrument was used to determine the surgical approach. Under the local anesthesia with $1 \%$ lidocaine, the skin in puncture point was cut and the patient was asked to hold his breath. The microwave electrode was implanted into the splenic neoplasm under the guidance of ultrasound, followed by ablation after intravenous anesthesia with propofol and ketamine. After ablation of each needle, the needle passage was ablated for 3-5 min until the ultrasound image showed that the ablation area reached the capsule and the capsule of spleen was slightly sunken. After the needle was withdrawn, whether there was free liquid around the spleen or in the abdominal cavity was scanned. After ablation, the patient was asked to take a supine position, and sent back to the ward after there were no vital signs for $2 \mathrm{~h}$.

Evaluation indexes. The splenic hemodynamics of patients in both groups was detected. The indexes included the arterial velocity of spleen (splenic arterial trunk, hilum of spleen, and arteries in intermediate zone and peripheral zone), diameter velocity and flow of splenic venous trunk were measured. The ablation volume was observed and measured by two experienced physicians in the ultrasound department. Ablation volume=total spleen volume before treatment-retention volume; ablation ratio=ablation volume/total spleen volume; 1-week shrink ratio $=($ ablation volume-volume of ablation area after 1 week)/ablation volume.

A total of $2 \mathrm{ml}$ peripheral blood was drawn from patients before treatment and at 3,7 and $14 \mathrm{~d}$ after treatment, and the peripheral blood cell count was detected, including the white blood cell, red blood cell and platelet counts. The complications of patients after treatment were observed, including the pleural effusion, increased blood amylopsin and hemoglobinuria, etc.; patients were followed up for 5 years, and the survival time and survival rate of patients in both groups were recorded.

Statistical analysis. Statistical Product and Service Solutions (SPSS) 19.0 (SPSS, Inc., Chicago, IL, USA) software was use for data processing. Measurement data were presented as mean \pm standard deviation. Comparison between groups was done using One-way ANOVA test followed by post hoc test (least significant difference). Enumeration data were presented as percentage, and chi-square test was used. And Kaplan-Meier survival analysis was performed. $\mathrm{P}<0.05$ was considered to indicate a statistically significant difference.

\section{Results}

Hemodynamic comparisons. Comparisons of splenic hemodynamic indexes of patients between the two groups.

The peak velocities of splenic arterial trunk, hilum of spleen, intermediate zone and peripheral zone in observation group were significantly lower than those in control group $(\mathrm{P}<0.05)$, and the diameter, velocity and flow of splenic vein were also obviously lower than those in control group $(\mathrm{P}<0.05)$ (Tables II and III).

Peripheral blood cell counts. Changes of peripheral blood cell counts were explored before treatment and at 3, 7 and 14 days after treatment. 
Table I. Comparisons of general data between the two groups.

\begin{tabular}{|c|c|c|c|c|}
\hline Item & Control group $(\mathrm{n}=31)$ & Observation group $(n=31)$ & $t / \chi^{2}$ & P-value \\
\hline Sex (male/female) & $17 / 14$ & $15 / 16$ & $0.065^{\mathrm{a}}$ & 0.799 \\
\hline Age (years) & $30-75$ & $30-78$ & & \\
\hline Average age (years) & $48.69 \pm 8.69$ & $49.04 \pm 8.53$ & $0.160^{\mathrm{b}}$ & 0.873 \\
\hline \multicolumn{5}{|l|}{ Type (n, \%) } \\
\hline Primary & $28(90.32)$ & $26(83.87)$ & $0.144^{\mathrm{a}}$ & 0.705 \\
\hline Metastatic & $3(9.68)$ & $5(16.13)$ & & \\
\hline
\end{tabular}

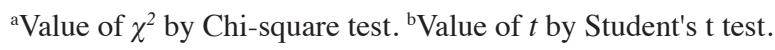

Table II. Comparisons of peak velocities of splenic artery of patients between the two groups $(\mathrm{cm} / \mathrm{sec})$.

\begin{tabular}{lccccc}
\hline Group & $\mathrm{n}$ & Trunk & Hilum of spleen & Intermediate zone & Peripheral zone \\
\hline Observation group & 31 & $87.73 \pm 3.05$ & $54.43 \pm 3.63$ & $35.23 \pm 3.56$ & $19.58 \pm 2.57$ \\
Control group & 31 & $94.24 \pm 3.37$ & $62.86 \pm 3.78$ & $42.56 \pm 3.47$ & $22.56 \pm 2.48$ \\
$t$ & & 7.947 & 8.956 & 8.209 & 4.646 \\
P-value & $<0.001$ & $<0.001$ & $<0.001$ & $<0.001$ \\
\hline
\end{tabular}

Table III. Comparisons of hemodynamic indexes of splenic vein between the two groups.

\begin{tabular}{lcccc}
\hline Group & $\mathrm{n}$ & Diameter of splenic vein (min) & Velocity of splenic vein (ml) & Flow of splenic vein (n) \\
\hline Observation group & 31 & $0.87 \pm 0.04$ & $25.43 \pm 2.53$ & $573.23 \pm 28.56$ \\
Control group & 31 & $0.91 \pm 0.07$ & $28.86 \pm 2.76$ & $599.56 \pm 28.47$ \\
$t$ & & 2.762 & 5.101 & 3.635 \\
P-value & & 0.008 & $<0.001$ & 0.001 \\
\hline
\end{tabular}

After treatment, the white blood cell and platelet counts in both groups were significantly increased compared with those before treatment, and the counts in observation group were obviously higher than those in control group $(\mathrm{P}<0.05)$. There were no significant changes in the red blood cell counts in both groups before and after treatment $(\mathrm{P}>0.05)$ (Tables IV, $\mathrm{V}$ and VI).

Effectiveness of ablation. The ablation volume, ablation ratio and 1-week shrink ratio in both groups had no significant differences $(\mathrm{P}>0.05)$ (Table VII).

Postoperative complications. Incidence rates of complication after operation were compared between the two groups. The incidence rate of complications in observation group $(3.23 \%)$ was significantly lower than that in control group (32.26\%) $(\mathrm{P}<0.05)$ (Table VIII).

Survival analysis. The average survival time was (38.45 \pm 9.26$)$ months in observation group and $(37.87 \pm 9.15)$ months in control group, and there was no significant difference between the two groups $(\mathrm{P}>0.05)$. The 5-year survival rate was $61.29 \%$ $(19 / 31)$ in observation group and $58.06 \%(18 / 31)$ in control group, and there was no significant difference between the two groups $(\mathrm{P}>0.05)$.

\section{Discussion}

Splenic neoplasm is the most serious spleen disease, but rare in clinic. Traditionally, splenic neoplasm is treated with splenectomy combined with postoperative radiotherapy and chemotherapy. However, the efficacy is poor because it is not sensitive to radiotherapy and chemotherapy, and it can transfer to the liver and lymph nodes in a short period. Moreover, the explosive infection, the most dangerous complication, often occurs after splenectomy. As a result, the prognosis is poor and the patient's survival rate is low (7). With the deepening of the understanding of the spleen, it is found that retaining $25 \%$ spleen can maintain the normal function of the spleen, so minimally invasive treatment of retaining spleen is increasingly accepted, including partial splenic artery embolization and thermal ablation, but the former can easily lead to postoperative liver failure, splenic abscess, portal vein thrombosis, peritonitis and other complications (8-11). The energy transfer of microwave ablation is not affected by the loss of water and carbonization, and less affected by the thermal precipitation 
Table IV. Comparisons of white blood cell counts at different time points between the two groups (x10 $\mathrm{g} / \mathrm{l})$.

\begin{tabular}{|c|c|c|c|c|c|c|}
\hline Group & $\begin{array}{c}\text { Before } \\
\text { treatment }\end{array}$ & $\begin{array}{c}3 \text { days } \\
\text { after treatment }\end{array}$ & $\begin{array}{c}7 \text { days } \\
\text { after treatment }\end{array}$ & $\begin{array}{c}14 \text { days } \\
\text { after treatment }\end{array}$ & F-value & P-value \\
\hline Observation group & $2.86 \pm 0.93$ & $5.89 \pm 1.03$ & $5.58 \pm 0.98$ & $4.48 \pm 0.97$ & $18.924^{\mathrm{b}}$ & $<0.001$ \\
\hline Control group & $2.85 \pm 0.92$ & $5.14 \pm 0.97$ & $4.85 \pm 0.95$ & $3.76 \pm 0.95$ & $10.612^{\mathrm{b}}$ & $<0.001$ \\
\hline$t$ & $0.043^{\mathrm{a}}$ & $2.951^{\mathrm{a}}$ & $2.978^{\mathrm{a}}$ & $2.953^{\mathrm{a}}$ & & \\
\hline P-value & 0.966 & 0.004 & 0.004 & 0.004 & & \\
\hline
\end{tabular}

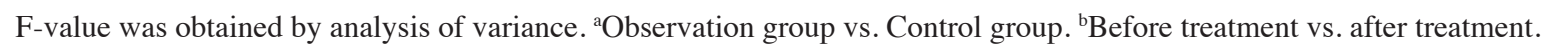

Table V. Comparisons of red blood cell counts at different time points between the two groups (x10 $\mathrm{g} / 1)$.

\begin{tabular}{|c|c|c|c|c|c|c|}
\hline Group & $\begin{array}{c}\text { Before } \\
\text { treatment }\end{array}$ & $\begin{array}{c}3 \text { days } \\
\text { after treatment }\end{array}$ & $\begin{array}{c}7 \text { days } \\
\text { after treatment }\end{array}$ & $\begin{array}{c}14 \text { days } \\
\text { after treatment }\end{array}$ & F-value & P-value \\
\hline Observation group & $3.85 \pm 0.87$ & $3.79 \pm 0.83$ & $3.63 \pm 0.76$ & $3.73 \pm 0.88$ & $1.907^{\mathrm{b}}$ & 0.078 \\
\hline Control group & $3.83 \pm 0.85$ & $3.74 \pm 0.88$ & $3.64 \pm 0.75$ & $3.72 \pm 0.87$ & $1.893^{\mathrm{b}}$ & 0.081 \\
\hline$t$ & $0.092^{\mathrm{a}}$ & $0.230^{\mathrm{a}}$ & $0.052^{\mathrm{a}}$ & $0.045^{\mathrm{a}}$ & & \\
\hline P-value & 0.927 & 0.819 & 0.959 & 0.964 & & \\
\hline
\end{tabular}

F-value was obtained by analysis of variance. ${ }^{a}$ Observation group vs. Control group. ${ }^{b}$ Before treatment vs. after treatment.

Table VI. Comparisons of platelet counts at different time points between the two groups ( $\left.\mathrm{x} 10^{9} \mathrm{~g} / \mathrm{l}\right)$.

\begin{tabular}{|c|c|c|c|c|c|c|}
\hline Group & $\begin{array}{l}\text { Before } \\
\text { treatment }\end{array}$ & $\begin{array}{c}3 \text { days } \\
\text { after treatment }\end{array}$ & $\begin{array}{c}7 \text { days } \\
\text { after treatment }\end{array}$ & $\begin{array}{c}14 \text { days } \\
\text { after treatment }\end{array}$ & F-value & P-value \\
\hline Observation group & $48.26 \pm 3.74$ & $57.78 \pm 3.43$ & $78.94 \pm 3.23$ & $104.29 \pm 4.68$ & $9.812^{\mathrm{b}}$ & $<0.001$ \\
\hline Control group & $48.75 \pm 3.68$ & $49.98 \pm 3.42$ & $70.36 \pm 3.38$ & $95.64 \pm 4.53$ & $6.431^{\mathrm{b}}$ & $<0.001$ \\
\hline$t$ & $0.520^{\mathrm{a}}$ & $8.966^{\mathrm{a}}$ & $10.218^{\mathrm{a}}$ & $7.394^{\mathrm{a}}$ & & \\
\hline P-value & 0.605 & $<0.001$ & $<0.001$ & $<0.001$ & & \\
\hline
\end{tabular}

F-value was obtained by analysis of variance. ${ }^{a}$ Observation group vs. Control group. ${ }^{b}$ Before treatment vs. after treatment.

Table VII. Comparison of ablation effect between the two groups.

\begin{tabular}{lcccc}
\hline Group & $\mathrm{n}$ & Ablation volume $(\mathrm{ml})$ & Ablation ratio (\%) & 1-week shrink ratio (\%) \\
\hline Observation group & 31 & $98.73 \pm 8.05$ & $12.83 \pm 5.63$ & $7.63 \pm 2.56$ \\
Control group & 31 & $99.24 \pm 8.37$ & $13.26 \pm 5.78$ & $7.56 \pm 2.47$ \\
$t$ & & 0.245 & 0.297 & 0.110 \\
P-value & & 0.807 & 0.767 & 0.913 \\
\hline
\end{tabular}

Table VIII. Comparisons of complications after operation between the two groups (n, \%).

\begin{tabular}{|c|c|c|c|c|c|c|c|}
\hline Group & $\mathrm{n}$ & $\begin{array}{l}\text { Pleural } \\
\text { effusion }\end{array}$ & $\begin{array}{c}\text { Increased } \\
\text { blood amylopsin }\end{array}$ & Hemoglobinuria & $\begin{array}{l}\text { Incidence rate } \\
\text { of complications }\end{array}$ & $\chi^{2}$ & P-value \\
\hline Observation group & 31 & $0(0.00)$ & $0(0.00)$ & $1(3.23)$ & $1(3.23)$ & & \\
\hline Control group & 31 & $2(6.45)$ & $4(12.90)$ & $4(12.90)$ & $10(32.26)$ & 7.073 & 0.008 \\
\hline
\end{tabular}


due to blood perfusion. In addition, the ablation area is larger, so it is widely used in the treatment of hepatocellular carcinoma with effective effect, but less used in splenic tumor. However, with the emergence of water-cooled microwave electrode technique, the traditional microwave ablation can remove more organ tumors with rich blood supply, so its feasibility is increased (12).

Until now, there are few reports about hemodynamic and blood cell comparisons in splenic tumors. But it is important to note that many patients with splenic tumors are complicated with hypersplenism (13-15), in which disease, the hemodynamic and blood cell are used as indicators to evaluate the therapeutic effect. Interestingly, we found that the hemodynamics and blood cells in patients with splenic tumors were abnormal, similar to those with hypersplenism. Accordingly, we compared hemodynamic and blood cell between the open and percutaneous approaches. The results of this study showed that the white blood cell and platelet counts in both groups were significantly increased compared with those before treatment, and the counts in observation group were obviously higher than those in control group $(\mathrm{P}<0.05)$. However, there were no significant changes in the red blood cell counts in both groups $(\mathrm{P}>0.05)$.

Peripheral platelet count will be affected by the high hemodynamic status of the spleen. Generally, the larger the diameter and flow of splenic vein are, the lower the white blood cell count will be. The retention theory argues that the portal vein pressure will affect the retention time of blood cells in the spleen. The higher the velocity of splenic artery is, the wider the diameter of splenic vein is and the larger the blood flow of splenic vein is, the lower the platelet count will be (16). The research results showed that the peak velocity of splenic artery in observation group was significantly lower than that in control group after 1 week of treatment, and the diameter, velocity and flow of splenic vein were significantly lower than those in control group $(\mathrm{P}<0.05)$. The ablation rate, ablation ratio and 1 -week shrink ratio were not significantly different in the two groups $(\mathrm{P}>0.05)$. The reason may be that ultrasound-guided percutaneous microwave ablation can monitor the ablation process in real time. In this condition, the ablation can be more accurate, ablation area overlapping can be avoided, damage to the surrounding organs can be prevented, and hemostatic effect can be immediately achieved. Besides, the water-cooled microwave energy can pass more deeply in the tissues, forming a greater range of ablation and reducing the arteriovenous flow and velocity (17). The ablation effect of ultrasound-guided percutaneous microwave ablation is not lower than that of open ablation mainly because the spleen blood flow is rich and fast, greatly affecting the ablation volume. As a result, the advantage of laparotomy is not prominent. Ultrasound-guided percutaneous microwave ablation can effectively reduce the high hemodynamic status of the spleen, thereby increasing the peripheral blood cell count.

The incidence rates of side effects and complications in observation group were significantly lower than those in control group $(\mathrm{P}<0.05)$. On the one hand, the ablation has no imaging guidance, and the distance between the two needles will be too close or crossed, causing ablation area overlapping. Moreover, the needle depth is not easy to be controlled, having an impact on the surrounding organs. What's more, the open microwave ablation surgery lasts longer and has larger trauma, which is likely to cause a variety of postoperative complications (18). On the other, the ultrasound-guided percutaneous microwave ablation can create the conditions for the single needle ablation of the specific coagulation volume, and accurately calculate the entry volumes, in which the condition, the ablation area overlapping can be avoided, resulting in relatively lower incidence of postoperative complications (19).

The curative effects of ultrasound-guided percutaneous microwave ablation in the treatment of splenic neoplasm are significant. This therapy can increase the peripheral blood cell count and improve the splenic blood flow and coagulation function, which play a role in the regulation of the patient's body status. The 5-year survival rate of patients is higher compared with open ablation and the ultrasound-guided percutaneous microwave ablation is characterized by the small trauma, lower incidence rates of adverse reactions and complications and better safety.

In conclusion, ultrasound-guided percutaneous microwave ablation is characterized by the small trauma, definite efficacy and fewer complications in the treatment of splenic neoplasm, which is safe and feasible, and can improve the prognosis and increase patients' survival rate. However, there were still many shortcomings in this study; for example, the small sample size caused bias inevitably, so the sample size should be further expanded for in-depth research.

\section{Competing interests}

The authors declare that they have no competing interests.

\section{References}

1. Xu B, Xie X, Zhou X, Zhai M and Yang W: Spontaneous rupture of primary splenic angiosarcoma: A case report. Oncol Lett 10: 3271-3273, 2015.

2. Carlini M, Spoletini D, Castaldi F, Giovannini C and Passaro U: Laparoscopic resection of splenic flexure tumors. Updates Surg 68: 77-83, 2016.

3. Tarchouli M, Bounaim A, Ratbi MB, Belhamidi MS, Bensal A, Aitidir B, Boudhas A, Ali AA and Sair K: Gastric leiomyosarcoma simulating splenic hilum tumor: Report of a case. Pan Afr Med J 21: 263, 2015 (In French).

4. Baccarani U, Pravisani R, Luigi Adani G, Lorenzin D, Cherchi V, Toniutto P and Risaliti A: Safety and efficacy of splenic artery embolization for portal hyperperfusion in liver transplant recipients: A 5-year experience. Liver Transpl 21: 1457-1458, 2015.

5. Yu X, Li H, Jin C, Fu D, Di Y, Hao S and Li J: Splenic vessel preservation versus Warshaw's technique during spleen-preserving distal pancreatectomy: A meta-analysis and systematic review. Langenbecks Arch Surg 400: 183-191, 2015.

6. Poggi G, Tosoratti N, Montagna B and Picchi C: Microwave ablation of hepatocellular carcinoma. World J Hepatol 7: 2578-2589, 2015.

7. Chung KM, Lau HY and Lau WY: Ectopic splenic tissues mimicking gastro-intestinal stromal tumour in a patient after splenectomy for a giant epithelial cyst of spleen: A case report. Int J Surg Case Rep 14: 13-15, 2015.

8. Di Sabatino A, Carsetti R and Corazza GR: Post-splenectomy and hyposplenic states. Lancet 378: 86-97, 2011.

9. Wood BJ and Bates S: Radiofrequency thermal ablation of a splenic metastasis. J Vasc Interv Radiol 12: 261-263, 2001.

10. Marangio A, Prati U, Luinetti O, Brunetti E and Fìlice C: Radiofrequency ablation of colorectal splenic metastasis. AJR Am J Roentgenol 178: 1481-1482, 2002.

11. Yu J, Liang P, Yu X, Wang Y and Gao Y: Ultrasound-guided percutaneous microwave ablation of splenic metastasis: Report of four cases and literature review. Int J Hyperthermia 27: 517-522, 2011. 
12. Yu J, Liang P, Yu X, Cheng Z, Han Z, Mu M and Liu Y: Clinical evaluation of ultrasound-guided percutaneous microwave ablation of splenic tumors. Nan Fang Yi Ke Da Xue Xue Bao 35: 333-337, 2015 (In Chinese).

13. Liu Q, Song Y, Zhou N, Xu X and Wang Z: Radiofrequency ablation of splenic tumors: A case series. J Gastrointestin Liver Dis 22: 105-108, 2013.

14. Carr JA: Splenic marginal zone lymphoma masquerading as cirrhotic hypersplenism for seven years. Can J Gastroenterol 26: 123-124, 2012.

15. Iriyama N, Horikoshi A, Hatta Y, Kobayashi Y, Sawada S and Takeuchi J: Localized, splenic, diffuse large B-cell lymphoma presenting with hypersplenism: Risk and benefit of splenectomy. Intern Med 49: 1027-1030, 2010.

16. Jiang X, Gao F, Ma Y, Feng S, Liu X and Zhou H: Percutaneous microwave ablation in the spleen for treatment of hypersplenism in cirrhosis patients. Dig Dis Sci 61: 287-292, 2016.
17. Li M, Yu X, Liang P, Dong B and Liu F: Ultrasound-guided percutaneous microwave ablation for hepatic malignancy adjacent to the gallbladder. Int J Hyperthermia 31: 579-587, 2015

18. Hatzidakis A, Zervakis N and Krokidis M: Fatal arterial hemorrhage after microwave ablation of multiple liver metastases: The lessons learned. Interv Med Appl Sci 5: 140-143, 2013.

19. Han ZY, Liang P, Yu XL, Cheng ZG, Liu FY and Yu J: Ultrasound-guided percutaneous microwave ablation of sporadic renal angiomyolipoma: Preliminary results. Acta Radiol 56: 56-62, 2015. Attribution-NonCommercial-NoDerivatives 4.0 International (CC BY-NC-ND 4.0) License. 